\title{
Study on Development Patterns of Cultural Industry Park
}

\author{
Xuefeng Zhao \\ The College of Architecture and Civil Engineering \\ Beijing University of Technology \\ Beijing, P R. China \\ zhaoxuefeng@bjut.edu.cn
}

\author{
$\mathrm{Li} \mathrm{Xu}$ \\ School of economics and Management \\ Beijing Jiaotong University \\ Beijing, P R. China \\ lilyxl@263.net
}

\begin{abstract}
Cultural industry is a rising industry that could speed up the change of economic growth ways, also the cultural industry park is the important carrier to nurse the cultural industry. The western of China has advantaged qualifications and good opportunities to develop cultural industry. Combined with the western's featured resources, this dissertation focused on three development patterns which are driven pattern of cultural resources driven, major cities-growth pole pattern and union driven pattern. They could provide theoretical analysis and realistic choices to develop cultural industry parks.
\end{abstract}

Keywords- The western China; Cultural industry; Cultural industry park; Industrial cluster; Cultural resource

In recent years, the cultural industry has experienced a great development in China. The marketization not only adds weight to advanced cultures, improves the quality of cultural products, accelerates the spread of fine cultural heritage and enrich people cultural choices, but also could promote economic growth and restructuring as a new economic increasing point, so it plays an important role in the regional competition.

But the overall situation does not seem balanced in the regions of China. The culture industry bloomed in developed cities such as Beijing, Shanghai and Guangdong, and became the new economic increasing point. Meanwhile, cities like Hangzhou, Nanjing, Qingdao and Dalian have established cultural industry bases or demonstration parks which have geographical features based on their resources to improve the development of cultural industry. Based on the strong support of regional economics, the Eastern regions have a distinct advantage to develop cultural industry. But it seems different in the West.

Based on the statistics for 2004, the differences between the east and west is huge. Firstly, in the terms of cultural industry units, the percentage of the west is $17.76 \%$. Secondly, in the terms of the distribution of employees, people who are occupied in the cultural industry only account for $1.32 \%$ of the whole employees, among which the west takes $14.4 \%$. And thirdly, in the terms of market share, the primary business revenue of the national cultural industry is 1.6878 trillion Yuan, which accounts for $98.05 \%$ of the whole year revenues, while the percentage of the west is $8.3 \%$. And fourthly, in terms of added value of cultural industry, the amount of added value of the west is 36 billion, takes $11.21 \%$ of the whole national added value of cultural industry. As we can see from the above, the regional development of Chinese cultural industry is imbalanced, and the problem is very prominent.

The successful experience of the developed countries and regions shows that centralized area is a successful model to foster the rapid growth of industry in the process of industrial development. To facilitate the use of technology, policy and market, promote the optimal allocation of resources, reduce the cost of coordination and upgrade the industry's overall image and competitiveness, we should establish the cultural industry to gather culture, creative, technology and talents in the same place. The centralized area is a developing trend of modern industry. As the important base of cultural industry, the cultural industry park should research the patterns of the western cultural industry; find the laws of development based on the west features to promote regional development.

\section{THE RELATED RESEARCHES OF CULTURAL INDUSTRY PARK}

Research on the industry park began in the concept of industrial clusters, theorized by British economist Marshall. According to the theory, the formation of industry parks depends on the basic objectives of the external scale economies. Many related companies were gathered together to share factors of production, reduce the costs of production; facilitate the coordination of enterprises, which results in complementary effect. Because of the effect we can create an environment to incentive continuous innovation and the development of business, and upgrade the overall innovation capability of the regional industry [1].

Current research on the cultural industry park primarily focused on the mechanism, features, and other aspects of the park. John Montgomery summarized the three points that lead to the success of the cultural industry, which are "activity, form and meaning". Comparing the four periods of development, he researched how the cultural industry could be a way of urban regeneration. And the research of Florida and Mitchell showed that the creative industry tended to concentrate to cities which have high open concentration, high tolerance, low entry barriers, cultural diversity and improve public services, especially in large urban areas. In addition, the research of Zukin - Molotch and Caves showed that the locations of creative industries tend to be the old warehouses, old factories of metropolitan areas and other inner city slums.

There are some scholars who discussed the conversion of industry park spaces, such as Markusen and King. They 
thought the original industry park was generally located in the old town, where many poor and infamous artists or novelists lived. When these places developed into some kinds of scale and became more and more influential, they began to attract well-known artists and wealthy customers, and then became the fashionable area of high consumption that lead to skyrocketing rents [2]. The loose, free and vibrant atmosphere changed into unfamiliar. Thus, some young artists migrated to the surrounding areas.

In the western regions of China, just relying on market mechanisms is not enough to develop the cultural industries and key industrial clusters. It needs the assistance of government power to guide the geographic concentration of specific industries; create new industry clusters and foster the network of industrial clusters to get higher productivity and competitive advantages. Therefore, in order to establish the development model of cultural industry in western regions, we should learn from the existing research experiences, and combine with the western Chinese features to explore a way to develop cultural industry.

\section{THE ADVANCES AND OPPORTUNITIES OF DEVELOPING CUlTuRAL INDUSTRY PARK IN WESTERN CHINA}

There must be some certain potential competitiveness which can help to promote the western Chinese cultural industry. The factors of production, market conditions, related and supporting industries, business strategy, government and potential opportunities play an important role.

A. The abundant resources provide the essential productive factors for the cultural industry

Compared with other industries, cultural industry puts more emphasis on new creative ideas, unique experiences rather than the cost advantages [4]. Culture has its own features, such as local, high cost of imitating, can't be replicable and its products and services are based on the depth excavation. This internal logic determines that the development pattern of cultural industry depends strongly on the cultural resources.

The western regions of China have rich resources, including natural resources, historical cultural resources and national cultural resources which are the foundation and the necessary prerequisite of industrial development. The rich resources in west, such as minorities' colorful cultures and exotic mystery of ethnic customs which accumulated in the long process of history, are very exclusive. And they can provide excellent cultural resources for the diversified competition with the eastern China.

B. The rapid growth of national economy can foster an extensive consumer market for the cultural industry park

According to the prediction of experts worked in the State Statistical Bureau, Chinese economy is on the road of rapid development and it will last a long time. As the level of national income continued to increase, new consumption peak is coming. According to Maslow's hierarchy of needs, people who has met the physiological and security needs would drop the needs of these two, while the spirit requirement would increase significantly. The rapid growth of national economy could provide people adequate food and clothing, and then the spirit requirement would grow rapidly, and consumption structure will continue to upgrade. Cultural consumption will truly become the main force driving the consumption structure, so as to cultivate the cultural industry a wide range of consumer markets.

\section{The rapid development of information technology could provide strong support for the cultural industry}

The information networks that based on computer, information and modern communication technology are experiencing a rapid development, which makes the spread of culture and communication more convenient. And based on which, the western culture could break the limit of time and space, and spread more wide and faster. Information network infrastructure makes the development of cultural industries have been well improved, and the promotion of cultural industries was accelerated.

\section{National preferential policies could be a positive role in promoting the development of cultural industry}

In order to change the imbalance in regional development appropriately, China has developed a large number of preferential policies for the west, including tax incentives and so on. In addition, the government also issued documents on the development of western cultural industry to provide guidance and planning, all of which will go to make up the uncertainly and ineffective direction of the west. These policies, advice and planning is also to a great extent to promote the development of western cultural industry.

\section{THREE KINDS OF PATTERNS OF THE WESTERN CULTURAL INDUSTRY PARK DEVELOPMENT}

The cultural industry is typical pattern of the development of modern economy which is people-oriented. Richness accumulation of the culture and the individual creative spirit is the key resources of this industry. So making the best use of advantaged resources to attract cultural industry professionals gather together to form the increase of cultural resources, thus the formation of cultural industry park is an effective way to develop China's cultural industry. In the occasion of China's industrial structural adjustment, there will be some ways (fully excavation of the western culture resources; improving the overall strength of technology 、 art - humanities; attracting the cultural industries talent to concentrate) to improve the economic competitiveness of cities by promoting the upgrading of industrial structure, further enhancing the innovation capability as a result of cultural industrial development.

\section{A. Pattern of the Characteristic Culture Resources Driven}

Vast primitive cultural resources hidden in the west of our country lay a solid material foundation for the development of the cultural industry. The Ethnic \& Cultural Resources - the Historical \& Cultural Resources and the 
Natural \& Cultural Resources most of which are still in primitive state, that is to say, they aren't opened up effectively. In the historical development of the western area is not only the multi-ethnic coexistences, but also many small nations standing everywhere, have become features of the western cultural diversity. In history, the western region had been witnessing a series of small nations, namely, Uighur, Turkic, Tuguhun, Tibetan, Western Xia, Dali, "Western thirty-six country" and so on. Last thousand years, through continuous migration, differentiation, integration, development and as a separate ethnic group, although many native peoples have disappeared, but the western culture especially the ethnic culture still be found traces of their culture. These known and unknown National cultural resources are all precious resources for the development of cultural industry. As shown in the following table. Plenty of cultural resources especially the rich folk cultural resources in some areas of western nations create an advantage for the development of cultural industry.

Meanwhile the Western culture is an open culture and used to be the focus of the internal culture communication for a long time. Western culture is not only the combination of the Western Minority Ethnic Culture and the Zhong Yuan Culture, but also the synthesis of the culture communion between China and West. By transforming many foreign cultures into its own nutrients, it can stay in sparky. There three important channels penetrates the west of China in history which makes Western Culture the core of internal culture. The Silk Road across the Northwest to the bank of Euro-Mediterranean is the first one; The second one is Tang Bo ancient course which links the Loess Plateau and Qinghai-Tibet Plateau; Another one is The Ancient Tea Horse Road ,crossing the Yunna-GuiZhou Plateau and passing the Qinghai-Tibet Plateau tend to Nepal and India even more distant place. In addition to the trade and exchanges between the people these three major channels have brought, they also promote cultural exchanges, the stream of Han culture flowing into western regions steadily. Old Europe Mediterranean culture, Guelabo culture, ancient Indian culture, Central Asia culture and so forth have also in this collection. Opened-up culture makes it possible that the western culture contains many elements of foreign culture, which laid the foundation for the western culture to display itself to the whole world.

Table I The Proportion Interval State Of Western Minorities In Each Western Province

\begin{tabular}{|c|c|c|c|}
\hline & $<10 \%$ & $20 \%-50 \%$ & $50 \%$ \\
\hline Provinces & $\begin{array}{c}\text { Chongqing, Gansu } \\
\text { Sichuan, Shaanxi }\end{array}$ & $\begin{array}{c}\text { Guizhou, Guangxi } \\
\text { Yunnan } \\
\text { Ningxia,Qinghai } \\
\text { Inner Mongolia }\end{array}$ & Xinjiang, \\
Tibet
\end{tabular}

Given the advantages of the local culture resources, the most important development mode for the culture industry in the west is industrialized management of culture resources. On the basis of deeper mining of the western cultural resources forming the ecological tourism park and combining the attractive effectiveness for tourists of this park we can further expand the resources actively, explorer the further development of the industry chain in depth to form an integrated business model which is on the expansion of visual arts (painting, photography and sculpture antiques), and cultural capital (archaeological sites, museums, libraries, exhibition halls, etc.), traditional cultural expressions (art and crafts, festivals and festivals), the performing arts (with the local cultural characteristics of the performing arts brand). This integrated business model will not only be good for opening up the western cultural resources, but also do some better for the formation of the theme park which is diversified and based on the eco-tourism park, the further strengthen of cultural characteristics brand and the greater creation of value.

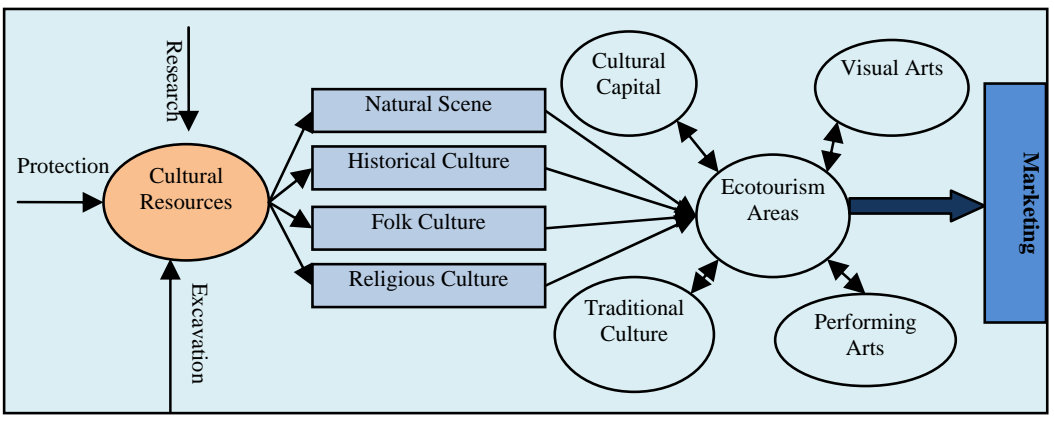

Fig 1 Pattern of the Characteristic Culture Resources Driven

\section{B. Focus cities-the pattern of Growth Poles}

There are still large gaps between the western and eastern regions in the current overall level of development. 
Still, under the background of the Develop-The-West strategy, the focus cities showing rapid economic development have conducted some exploration in the cultural industry, and have shaped a series of social influential brand. The cities have grown to be locomotive of the western economic development include Chongqing, Chengdu, Xi'an, Kunming, Yulin, Urumqi, Lanzhou, Xian yang, Guiyang, Qujing, Mianyang, Baoji, Deyang, Yan'an. In recent years through the implementation of the Talent Strategy to draw the local universities, research institutions attention, we have built a good educational environment for educating people which will be the foundation for the formation of the park. The western focus cities can construct an industry cluster based on cultures and realize the integrative development of the culture -economy by the following three ways. Firstly, bring along the related industries and extend the cultural industry chain by the industrialized management of culture products and resources. There are two examples: such as Kunming, Yunnan province, takes advantage of its unique status of big touring province through its cultural resources to drive its TV entertainment, transportation, catering, hotels and other industries; Another example, Ningxia Yongning Hui District drives the tourist, handmade, performing arts, culture creation and so forth, to develop by means of constructing its own culture industry park. Secondly, promote regional economic development and improve the city image and investment environment via the development of cultural industry. Such as the UK city, Manchester, originally a heavy industry city, with the depletion of resources, restructured timely to develop its sports industry and established a sports industry represented by Manchester City football club, finally end with the formation of distinctive industry park. Thirdly, drive other industries to develop by the cultural brand in existence, actually via the extension management of cultural brand to maximize the economic benefit. With the cultural industry we should breed a cultural brand with great market appeal, and then expand this brand to other industries to maximize brand value. Such as the Disney, used to be toy brand of the U.S., but it extends the brand to the publication, audio, video, travel, clothing, children's products and other fields. Also, making use of all kinds of Disney images it built theme parks and constructed a huge industry chain and cluster focused on Disney. Therefore, nurturing its own core brand and developing a strong cultural brand, with product brand association and deeper digging the potential of industrial growth, the western regions can bring into being a vertical concentration of industry chain and bring along the other related industries.

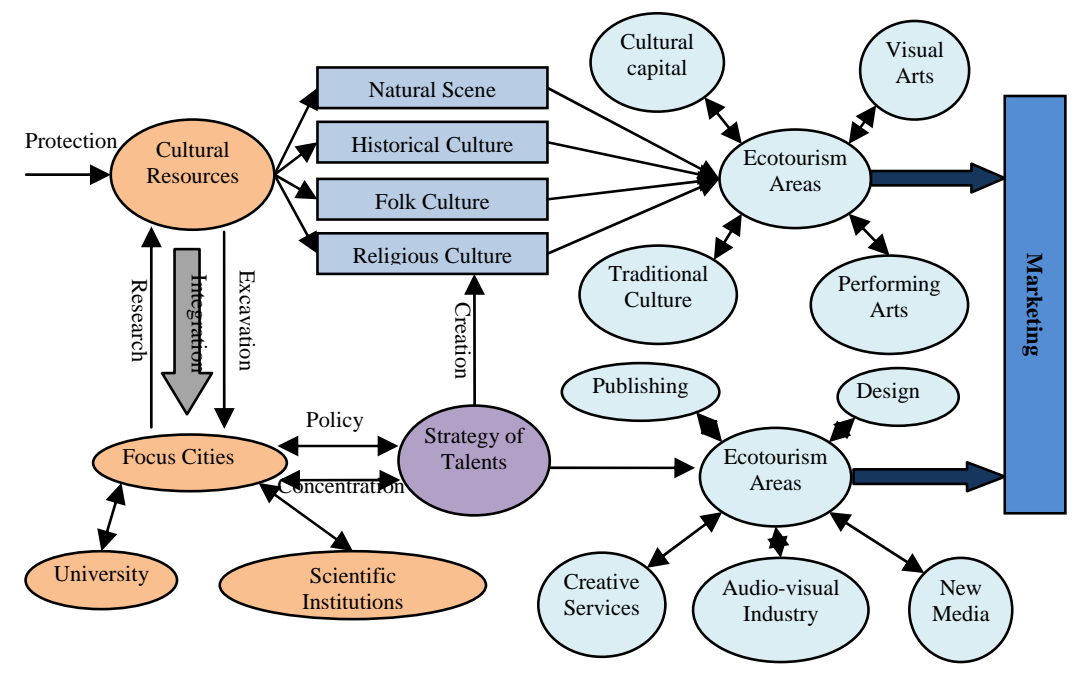

Fig 2 Focus cities-the pattern of Growth Poles

As can be seen from Figure 2, the pattern of Growth Poles in the western focus cities, on the one hand studies and digs the distinctive cultural resources deeply to perform integration development of cultural special resources; one the other hand attracts the outside creative talents to gather and pays attention to the strategic partnership namely learning, producing, studying, with universities and research institutes, meanwhile makes full use of creative ability and reprocesses the special resources so as to form the knowledge-intensive, technology-intensive and with a lead edge cultural industry. Moreover, we should apply creative knowledge to guide further development and utilization of cultural resources. Only in this way can we inject sustainability blood into the long-term continued development of Eco-Tourism Park.

\section{The pattern of Union Drive}

Western creative cultural industry should make use of other non-culture industries to expand cultural industry, form the cultural industry development alliance, finally, drive the development of cultural industry. For one thing, a relatively unique economic development zone has been 
constructed at present; it can be beneficial to the resource complementarity and mutual exchanges for the cities located in economic development zone. (For example, the strategic alliance of professionals, mutual visit and learning opportunities, integration of resources and technology)For another thing, there are advantages of relatively fast development of cultural industry, abundant financial strength and wide range market. Therefore, it is favorable for the development of the western Characteristic Culture Resources to form a strategic alliance in the west of china. Again, for the development of the western cultural industry, we should actively attract foreign capital, introduce foreign advanced technology and established a combined domestic and international strategic development model to provide power for the rapid development of the western cultural industry park and catch up with the east regions of china.

\section{1) Pattern of Economic Belt Driven}

At present there are three important economic belts in the western regions: First, the Cheng-Yu Economic Belt, adhering to the long-term cooperation, Sichuan province and Chongqing city built the Cheng-Yu Economic Belt led by Chengdu and Chongqing with the support of resource conditions and industrial base. As one of the most developed regions in western, Cheng-Yu Economic Belt's economic development has reached a relatively high level. With the Bank of China, State Development Bank and many other large regional financial offices, Cheng-Yu Economic Belt gradually formed the regional financial markets and property rights trading market based on the funds loan-deposit, inter-bank borrowing, securities trading and foreign exchange swap. Second, the West-Longhai-Lan Economic Belt, as the important region of the regional economic development identified by "the 10th Five-years overall Plan", at the same time, as the representative of traffic economy, the West-Longhai-Lan Economic Belt links the "three West" energy and heavy chemical base, Shanxi Guanzhong Cities, Gansu Hexi Lanbai Economic Regions and the Hexi Corridor spark economic zones with the Hetao region in inner Mongolia and the Northern slope economic regions of Tianshan Mountain in Chaidamu regions. Consequently the West-Longhai-Lan Economic Belt plays an important role in the western regional economic structure and the economic development of this zone bears important national significance----the western regions is one of the densest regions where the minority population distributes. With the economic development of the West-Longhai-Lan Economic Belt, the channels which ethnic minority areas use to communicate with the outside world have been broaden, the potential of economic development released and the support and promotion gained from the outside increasingly grow. The ethnic issue will be a positive element for the building of socialist harmonious society. Third, the Nanning-Guiyang-Kunming Economic Belt, centered on Nanning, Guiyang, Kunming, is a unique belt in the western regions which is a coastal littoral border district. So the Nanning-Guiyang-Kunming Economic Belt has a strong advantage of location. Guangxi, facing Southeast Asia and neighboring Hong Kong, Macao, has excellent conditions to construct harbors, and also is the conjunction of the southwest coastal regions and southwest regions. Thereby it can obtain the radiation and impetus from both the southeast economic circle and the south china economic circle; Guizhou, located in the hinterland of southwest, is the conjunction of western and central regions, and also is the gateway from southwest regions to the central south and southeastern regions; Yunnan, the most important channel to the outside world in the southwestern regions, together with the countries in Southeast Asia is described as "sharing the same edge of mountains and the same cognate of rivers". Yunnan will be the forefront of the integration of regional economy in Southwest and Southeast Asia once the China-ASEAN Free Trade Area is officially formed.

For the sake of cultural industry in western regions, we should make full use of pull and radiation effects provided by the three above economic belts. On the basis of the existing industrial bases and the implementation of the cultural industry development strategic alliances, we can build a cultural industry park which is advantages-complementary, features-distinctive and sharing-resource so that we can improve the overall development level of cultural industry in western regions.

\section{2) Pattern of East-West combination}

Given the favorable natural conditions in eastern China, in the field of technology introduction, capital, talents, securities market development and futures market, etc, it is the eastern China who is making the running. In contrast, under the conditions of poor economic base, slow development, it is difficult for the western regions to attract external funds, even worse there is a massive outflow of the original capital, talents and labor. Thus, the intrinsic motivation and foreign aid support of economic development were weakened. Even though in the process of the West Development, western China has achieved rapid development, compared to the eastern regions, there still are gaps between them especially in the respect of human resources, technology, and funds.

Western China has a unique cultural resource endowment. Through the integration of the eastern and western resource, we can form a loose network alliance which features complementary advantages and cooperation with proper division of labor.

3) Pattern of Chinese-foreign cooperation

The issue of capital has always been the bottleneck for a long time which restricts the development of cultural industry in Western. While there is a substantial increase in investment to the west in recent years, but for the vast western regions, it is far from enough to meet its real need to achieve rapid development for the cultural industry. With surge in investment, it not only burdens the financial pressure for the country but also is difficult to achieve the desired effect. With the international influence, the features of the western cultural resources have great room for development in the respect of foreign investment and advanced technology introduction.

Through international cooperation, it can help to open foreign markets further, expand the influence of our western culture industry and form an advantage of brand 
competition. In this pattern, we must take care to protect the dominant position of Chinese cultural resources. Culture, as the soft power of a country, its status has risen to a high degree of national strategies, so, to strengthen local cultural resources protection and sustainable development is its essential conditions.

\section{SUMMARY}

Coincided with opportunities, there is a great many of advantages for the development of cultural industry in western China. The development of cultural industry not only helps promote the western economic growth, industrial restructuring and upgrading, but also plays a positive role in the progress of western society and promoting the utilization of the rich cultural resources, so as to promote balance in culture and economy between east and west.

By means of its accumulative effect and scale effect, cultural industry park can greatly improve the layout and structure of cultural industry and optimize the structure of cultural industry, thus promoting the development of cultural industry. Therefore, the development of cultural industry in western China bears important strategic significance to the western economic development.

\section{REFERENCES}

[1] Chen Jianfeng, Tang Zhenpeng. Study review of foreign industry clusters Shanghai: Foreign Economics and Management, 2002:2-4

[2] Niu Weilin. International Cultural and Creative Industry Park Development Report [M].Beijing: China Renmin University Press, 2007

[3] Hua Jian. Industry Cluster and Knowledge Source-On the Cultural Creative Industries and Development of the inherent laws and power.[J]. Shanghai: Learned journal of Shanghai University, 2007

[4] Jin Yuanpu. Incubator and creative industry park [J]. Beijing: China culture journal, 2006

[5] Dan Zeng. Research on the development paths of the cultural industry in western China [J], Beijing: Literary Theory and Criticism, 2006 